\title{
Conflict Resolution in the Twenty-first Century: Principles, Methods, and Approaches
}

by Jacob Bercovitch and Richard Jackson

University of Michigan Press, August 4, 2009

ISBN: 9780472050628

http://tinyurl.com/bprur8w

US $\$ 32.50$

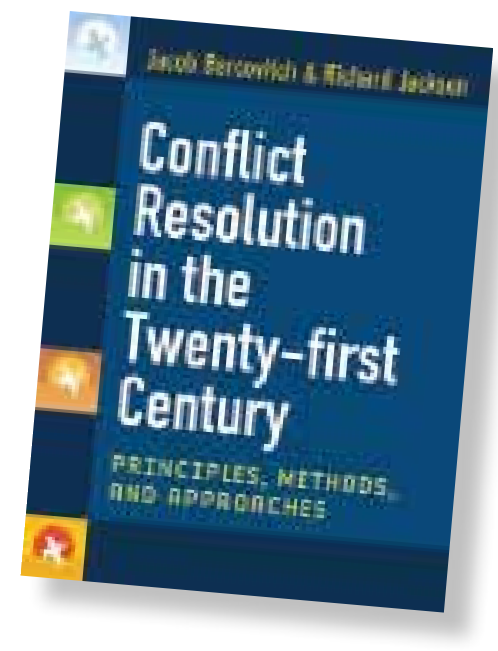

I

n Conflict Resolution in the Twenty-first Century: Principles, Methods, and Approaches, Bercovitch and Jackson create an accessible and well-organized analysis of the best approaches to resolving conflicts in the world today. Emphasizing fundamental changes in the nature of conflict following the Cold War, the authors present the argument that conflict resolution must also change. Their analysis characterizes pre1991 conflicts as primarily interstate conflicts or power struggles between states and insurgents, overseen and manipulated by the major powers. According to the authors, the collapse of the Soviet Union saw "the proliferation of ethnic, religious, cultural, and resource-driven conflicts as major threats to international peace." This shift rendered traditional methods of resolving conflicts practically obsolete, forcing innovative thinking to produce a new understanding of peace building.

Bercovitch and Jackson, both from the University of Canterbury, New Zealand, describe traditional approaches-international negotiation, conflict mediation, arbitration and adjudication, U.N. conflict resolution and peacekeeping-and explain how these methods must evolve to meet the needs of the modern world. They analyze new methods-preventive diplomacy, humanitarian intervention, regional tasksharing, nonofficial justice, and reconciliation-as approaches arising from a philosophy of participatory social interaction, which views peace as the result of positive cultural transformation rather than a state imposed by a paternalistic superstructure. Additionally, they view nongovernmental organizations as crucial actors in implementing this new methodology because of their moral credibility and independence from power politics. Concise, well-referenced and eloquent, this book outdistances other weightier tomes in defining a peace-building agenda for the future. $₫$

Reviewed by Cameron Macauley, CISR staff. 